\title{
Analisis Kebutuhan Batu Bara pada Unit Dryer dalam Pengeringan Pupuk NPK di PT AGS Medan
}

\author{
Analysis of Coal Needs in Dryer Unit for Drying NPK Fertilizer at PT AGS Medan \\ Dimas Frananta Simatupang $^{1 *}$, Yunianto ${ }^{1)}$, Erwin Dani Winata Sihaloho ${ }^{1)}$ \\ ${ }^{1)}$ Politeknik Teknologi Kimia Industri Medan, Teknik Kimia, Indonesia
}

*correspondence email: difratas@ ptki.ac.id

\begin{abstract}
Abstrak
PT. AGS Medan merupakan pabrik yang bergerak dalam produksi pupuk NPK yang salah satu produknya adalah formula 12.12 .17 dengan komposisi $12 \%$ unsur nitrogen, $12 \%$ unsur fosfor dan $17 \%$ unsur kalium. Salah satu tahapan dalam proses pembuatan pupuk NPK yaitu proses pengeringan. Jenis dryer yang digunakan adalah rotary dryer dengan putaran $5 \mathrm{rpm}$ dan kemiringan $20^{\circ}$. Pengering yang digunakan adalah udara panas yang berasal dari pembakaran batu bara jenis bitminious di dalam furnace. Untuk menentukan jumlah batu bara yang dibutuhkan dalam proses pengeringan pupuk NPK sebagai bahan bakar furnace maka diperlukan perhitungan jumlah panas. Pengambilan sampel, analisis kadar air dan suhu serta menghitung panas dengan prinsip neraca massa dilakukan dalam penelitian ini. Berdasarkan perhitungan yang telah dilakukan untuk mengeringkan pupuk NPK dengan kapasitas pupuk NPK $7000 \mathrm{~kg} / \mathrm{jam}$ dibutuhkan energi sebesar 6136268,402 Kkal/jam. Jumlah bahan bakar yang dibutuhkan untuk mengeringkan pupuk NPK adalah sebesar 789,219 kg/jam.
\end{abstract}

Kata kunci: batu bara; dryer; neraca massa; pupuk NPK

\begin{abstract}
PT. AGS Medan is a factory engaged in the production of NPK fertilizer where one of the products is 12.12.17 with a composition of $12 \%$ nitrogen, $12 \%$ phosphorus and $17 \%$ potassium. One of the stages in the process of making NPK fertilizer is the drying process. The type of dryer used is a rotary dryer with a rotation of $5 \mathrm{rpm}$ and a slope of $20^{\circ}$. The dryer used was hot air from burning bitminious coal in furnace. To determine the amount of coal needed in drying process of NPK fertilizer as furnace fuel, it was necessary to calculate the amount of heat. Sampling, analysis of moisture content and temperature then calculating heat with mass balance principles were carried out in this study. Based on the calculations that have been made to dry NPK fertilizer with an NPK fertilizer capacity of 7000 $\mathrm{kg} / \mathrm{hour}$, energy was required of $6136268.402 \mathrm{Kcal} / \mathrm{hour}$. The amount of fuel needed to dry NPK fertilizer is $789.219 \mathrm{~kg} / \mathrm{hour}$.
\end{abstract}

Keywords: Coal; Dryer; Mass balance; NPK fertilizer 


\section{Pendahuluan}

Peran batu bara sebagai sumber energi terus mengalami peningkatan dari tahun ke tahun terutama di kawasan Asia misalnya di India, batu bara menjadi sumber yang dominan sebagai penghasil energi [1,2], di Indonesia digunakan sebagai sumber daya untuk energi listrik pada Pembangkit Listrik Tenaga Uap [3] dan banyak juga ditemukan penggunaannya pada boiler sebagai penghasil uap panas [4]. Batu bara telah menjadi pemasok energi kedua terbesar setelah minyak dengan kontribusi $26 \%$ dari total konsumsi energi dunia dan diprediksi akan terus meningkat menjadi $29 \%$ pada tahun 2030.

Penggunaan batu bara di Indonesia cenderung menggunakan batu bara berjenis bitminious dan subitminious yang kualitasnya lebih tinggi dibandingkan batu bara lignit. Batu bara lignit dikenal kurang ekonomis dikarenakan sifatnya yang sangat berbeda tergantung pada asalnya dan juga hanya mengandung $40 \%$ komposisi dari total batu bara dan bahan baku yang dipasarkan dengan tingkat keamanan yang tinggi $[5,6]$. Berdasarkan tingkat kalori, distribusi batu bara di Indonesia yaitu batu bara kalori rendah (<5100 kal/gram) 326,40 miliar ton, kalori sedang (5100-6100 kal//gram) 82,26 miliar ton, kalori tinggi (6100-7100 kal/gram) 8,27 miliar ton dan kalori yang sangat tinggi (>7100 kal/gram) 2,11 miliar ton [7].

Tidak semua batu bara dapat digunakan sebagai bahan bakar untuk boiler tetapi berdasarkan atas HHV (High Heating Value). Jika nilai HHV rendah maka akan menghasilkan panas yang relatif rendah setelah terjadi pembakaran sehingga mempengaruhi performa dari boiler itu sendiri [8].
PT. AGS Medan merupakan salah satu industri pengolah pupuk NPK yang menggunakan batu bara untuk proses pembakaran dan pengeringan. Pupuk NPK merupakan hasil olahan dari pencampuran bahan-bahan yang sudah ditentukan dengan formulasi tertentu yang kemudian dibentuk menjadi granul dengan cara membasahi bahan-bahan dalam alat granulator. Salah satu produk pupuk NPK dari pabrik ini yaitu pupuk NPK formula 12:12:17 yang merupakan pupuk majemuk yang mengandung 3 unsur hara yakni nitrogen $12 \%$, fosfor $12 \%$, dan kalium $17 \%$. Pupuk ini didesain khusus untuk tanaman perkebunan yang mempunyai sistem gradual release (keluar secara bertahap) yang cocok untuk tanaman perkebunan khususnya untuk tanaman yang masih dalam pertumbuhan dan belum berbuah. Pemeliharaan tanaman yang optimal akan menentukan pertumbuhan dan produktivitas pada masa tanaman di lapangan. Kultur teknis yang paling utama pada saat pembibitan adalah pemupukan [9].

Untuk proses pengeringan pupuk NPK, PT. AGS Medan menggunakan rotary dryer di unit dryer. Proses pengeringan adalah proses perpindahan massa air atau pelarut lainya dari zat padat atau semi padat dengan menggunakan penguapan. Pengeringan merupakan bagian sangat penting dalam kegiatan industri yang memanfaatkan bahan bakar sebagai sumber energi. Rotary dryer adalah salah satu jenis mesin pengering yang secara khusus digunakan untuk mengeringkan aneka bahan padatan yang biasanya berbentuk tepung atau granul/butiran [10]. Bahan padatan dimasukkan dari ujung inlet melalui screw conveyor dan dikeringkan sepanjang tabung/drum yang berputar. Adanya 
kemiringan tabung dan sirip-sirip di dalam tabung/drum menyebabkan bahan akan keluar menuju ujung screw conveyor outlet. Penggunaan DCS (Distributed Control System) bertujuan untuk mengendalikan proses manufaktur secara terus menerus atau batch-oriented. DCS adalah suatu sistem kendali terpadu secara otomatis [9]. Rotary dryer paling cocok untuk mengeringkan material yang tidak mudah pecah dan tahan terhadap panas serta membutuhkan waktu pengeringan yang cepat. Rotary dryer memiliki keunggulan diantaranya dapat mengeringkan baik lapisan luar ataupun dalam dari suatu padatan, proses pencampuran yang baik, memastikan bahwa terjadinya proses pengeringan bahan yang merata, menghasilkan efisiensi panas tinggi dan kesinambungan operasi $[11,12]$.

Tujuan penelitian ini dilakukan adalah untuk menentukan banyaknya batu bara yang dibutuhkan untuk mengeringkan pupuk NPK PT AGS Medan menggunakan rotary dryer firebrick melalui banyaknya energi panas yang dihasilkan.

\section{Metode Penelitian}

Penelitian diawali dengan mengumpulkan data primer dari pabrik PT. AGS Medan tepatnya pada unit dryer pada proses pengeringan pupuk NPK formula 12.12.17. Data primer tersebut meliputi laju pupuk yang masuk ke dalam unit dryer, temperatur udara dan kadar pupuk NPK yang masuk serta keluar dari unit dryer. Pengambilan data primer dilakukan sebanyak lima kali dengan kondisi dan parameter yang sama.

\subsection{Alat dan Bahan}

Alat yang digunakan dalam penelitian ini adalah rotary dryer dengan kecepatan putar $5 \mathrm{rpm}$ dan kemiringan $20^{\circ}$, moisture analyzer tipe Ohous MB45, Infrared thermometer non-kontak EM520 dan furnace. Bahan yang digunakan sebagai sampel adalah pupuk NPK granular yang sudah melewati unit granulator dan pupuk NPK granular yang keluar dari unit dryer.

\subsection{Analisis Temperatur Pupuk NPK}

Pupuk NPK granular yang sudah melewati unit granulator dan pupuk NPK granular yang keluar dari unit dryer selanjutnya ditentukan temperaturnya dengan menembakkan sinar melalui alat Infrared thermometer non-kontak EM520 dan dicatat hasilnya.

\subsection{Analisis Kadar Air Pupuk NPK}

Sampel pertama adalah pupuk NPK granular yang sudah melewati unit granulator diambil secukupnya kemudian dimasukkan ke dalam wadah yang telah disiapkan. Kemudian sampel kedua adalah pupuk NPK granular yang sudah melewati unit dryer diambil secukupnya kemudian dimasukkan ke dalam wadah yang telah disiapkan. Masing-masing sampel secara bergantian dimasukkan ke dalam alat moisture analyzer sebanyak 5 gram. Moisture analyzer ditutup dan ditekan tombol start dengan suhu $160{ }^{\circ} \mathrm{C}$. Moisture analyzer akan berbunyi setelah 10 menit dan dicatat berapa besar kadar air pada pupuk NPK granular yang tertera pada alat.

\subsection{Perhitungan Neraca Massa}

Kesetimbangan materi (neraca massa) dapat dirumuskan pada sistem konservatif seperti yang ditunjukkan pada Gambar 1 dengan $F^{1}$ merupakan laju pupuk NPK masuk ke dryer, $\mathrm{F}^{2}$ merupakan laju pupuk NPK keluar dryer, $\mathrm{F}^{3}$ merupakan laju udara masuk ke dryer dan 
$\mathrm{F}^{4}$ merupakan laju udara keluar dari dryer. Perhitungan neraca massa seperti pada Gambar 1 digunakan untuk menentukan jumlah pupuk NPK yang keluar dari dryer dan menentukan kadar air yang teruapkan.

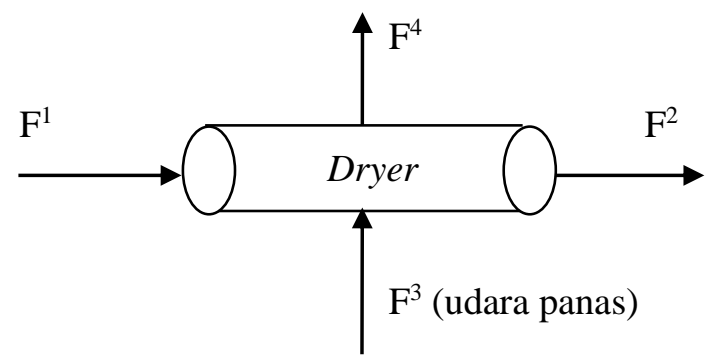

Gambar 1. Neraca Massa Proses Pengeringan Pupuk NPK Formula 12.12.17

\subsection{Penentuan Jumlah Udara Keluar}

Dryer

Untuk menentukan jumlah udara yang keluar dari unit dryer pada proses pengeringan pupuk NPK, diawali dengan menentukan debit aliran menggunakan persamaan (1). Kemudian menentukan massa udara dengan persamaan (2).

$$
\mathrm{Q}=\mathrm{A} \cdot \mathrm{V}
$$

dengan $\mathrm{Q}$ adalah debit aliran $\left(\mathrm{m}^{3} / \mathrm{jam}\right) ; \mathrm{A}$ adalah luas penampang $\left(\mathrm{m}^{2}\right) ; \mathrm{V}$ adalah kecepatan udara $(\mathrm{m} / \mathrm{s})[13]$.

$$
\mathrm{M}_{\text {udara }}=\text { Q. } \rho_{\text {udara }}
$$

dengan $m_{\text {udara }}$ adalah massa udara $(\mathrm{kg} / \mathrm{jam})$; $\mathrm{Q}$ adalah debit aliran $\left(\mathrm{m}^{3} / \mathrm{jam}\right)$ dan $\rho_{\text {udara }}$ adalah berat jenis udara $\left(\mathrm{kg} / \mathrm{m}^{3}\right)$.

Selanjutnya untuk menghitung jumlah udara yang keluar dari unit dryer pada proses pengeringan pupuk NPK dapat dihitung menggunakan persamaan (3).

$$
\mathrm{F}^{4}=\mathrm{F}^{3}+\mathrm{A}
$$

dengan $\mathrm{F}^{4}$ adalah laju udara yang keluar dari unit dryer; $\mathrm{F}^{3}$ adalah laju udara yang masuk ke unit dryer dan A adalah laju air yang teruapkan.
2.6. Penentuan Panas dan Kebutuhan Batu Bara pada furnace dalam Pengeringan Pupuk NPK

Sebelum menentukan panas yang digunakan pada proses pengeringan pupuk, terlebih dahulu ditentukan kapasitas panas dari komponen penyusun pupuk NPK formula 12.12.17 dengan metode Goodman [14].

Panas yang digunakan ( $\left.\mathrm{Q}_{\text {dibutuhkan }}\right)$ dalam proses pengeringan pupuk NPK formula 12.12.17 ditentukan menggunakan persamaan (4)

$$
\begin{array}{r}
\mathrm{Q}_{\text {dibutuhkan }}=\mathrm{Q}_{1}+\mathrm{Q}_{2} \ldots \ldots \ldots \ldots \ldots . . . . . .(4) \\
\mathrm{Q}_{\text {dibutuhkan }}=\mathrm{m}_{\mathrm{NPK}} \cdot \mathrm{C}_{\mathrm{pNPK}} . \Delta \mathrm{T}+\mathrm{m}_{\text {vapor }} \cdot \lambda
\end{array}
$$
$\mathrm{m}_{\mathrm{NPK}}$ adalah Berat pupuk NPK masuk ke dryer (kg/jam); $\mathrm{C}_{\mathrm{pNPK}}$ adalah panas molar NPK pada temperatur $328 \mathrm{~K} ; \Delta \mathrm{T}$ adalah selisih suhu NPK masuk dan keluar dryer $(\mathrm{K}), \mathrm{m}_{\text {vapor }}$ adalah massa air teruapkan ( $\mathrm{kg} / \mathrm{jam})$; dan $\lambda$ adalah nilai enthalphy of vaporization Air (kkal/kg).

Selanjutnya untuk menghitung jumlah bahan bakar batu bara yang dibutuhkan $\left(m_{b b}\right)$ untuk memanaskan udara pada pengeringan pupuk NPK digunakan persamaan (5).

$$
\begin{array}{r}
Q_{\text {bahan bakar }}=Q_{\text {dibutuhkan }} \\
m_{b b} \cdot N_{b b}=Q_{\text {dibutuhka }}
\end{array}
$$

dengan $\mathrm{N}_{\mathrm{bb}}$ adalah nilai kalor batu bara $s u b$ bitminous $=7777 \mathrm{kkal} / \mathrm{jam}[15]$.

\section{Hasil dan Pembahasan}

Data primer yang diperoleh langsung dari pabrik sangat penting untuk dapat menentukan kebutuhan batu bara yang digunakan dalam proses pengeringan pupuk NPK formula 12.12.17. Setelah diperoleh data primer maka dilanjutkan pengambilan sampel pupuk NPK granular yang sudah melewati unit granulator dan pupuk NPK granular yang keluar dari unit 
dryer. Sampel tersebut selanjutnya ditentukan temperatur dan kadar airnya.
Data-data tersebut ditunjukkan pada Tabel 1.

Tabel 1. Data Primer, Temperatur dan Kadar Air Pupuk NPK

\begin{tabular}{cccccccc}
\hline No & $\begin{array}{c}\text { Laju } \\
\text { Pupuk }\end{array}$ & \multicolumn{2}{c}{$\begin{array}{c}\text { Temperatur } \\
\text { Udara } \\
(\mathbf{k g} / \mathbf{j})\end{array}$} & \multicolumn{2}{c}{$\begin{array}{c}\text { Temperatur } \\
\text { Pupuk NPK }\end{array}$} & \multicolumn{2}{c}{$\begin{array}{c}\text { Kadar Air } \\
(\boldsymbol{\%})\end{array}$} \\
\cline { 3 - 8 } & In & Out & In & Out & In & Out \\
\hline 1 & 7000 & 138 & 67 & 44 & 66 & 4,48 & 1,83 \\
2 & 7000 & 137 & 64 & 45 & 65 & 4,48 & 1,82 \\
3 & 7000 & 136 & 66 & 43 & 64 & 4,47 & 1,86 \\
4 & 7000 & 136 & 67 & 44 & 65 & 4,46 & 1,84 \\
5 & 7000 & 136 & 66 & 45 & 63 & 4,45 & 1,83 \\
\hline
\end{tabular}

3.1. Penentuan Jumlah Pupuk NPK yang Keluar dari Dryer dan Kadar Air Teruapkan

Prinsip neraca massa digunakan untuk menentukan jumlah pupuk NPK yang keluar dari unit dryer dengan sistem konservatif seperti ditunjukkan pada Gambar 2 dengan $\mathrm{T}_{1}$ adalah temperatur pupuk NPK masuk ke dryer $\left({ }^{\circ} \mathrm{C}\right), \mathrm{T}_{2}$ adalah temperatur pupuk NPK keluar dari dryer $\left({ }^{\circ} \mathrm{C}\right), \mathrm{T}_{3}$ adalah temperatur udara panas NPK ke dryer $\left({ }^{\circ} \mathrm{C}\right), \mathrm{T}_{4}$ adalah temperatur udara panas NPK keluar dari dryer $\left({ }^{\circ} \mathrm{C}\right), \mathrm{W}^{1}{ }_{1}$ adalah kadar air pupuk NPK masuk ke dryer $\left({ }^{\%}\right), \mathrm{W}^{2}{ }_{1}$ adalah kadar air pupuk NPK keluar dari dryer $\left({ }^{\%}\right), \mathrm{W}^{1}{ }_{2}$ adalah kadar pupuk NPK masuk ke dryer $\left({ }^{\%}\right), \mathrm{W}^{2}{ }_{2}$ adalah kadar pupuk NPK keluar dari dryer ${ }^{\%}$ ), $\mathrm{F}^{1}$ adalah laju pupuk NPK keluar dari dryer (kg/jam), $\mathrm{F}^{2}$ adalah laju pupuk NPK keluar dryer $(\mathrm{kg} / \mathrm{jam})$ dan $\mathrm{F}^{3}$ adalah laju udara masuk ke dryer (kg/jam).

Berdasarkan pada Gambar 2, untuk menghitung laju pupuk NPK yang keluar dari dryer maka digunakan rumus neraca komponen NPK pada persamaan (6).

$$
\begin{gathered}
\mathrm{F}^{1} \cdot \mathrm{W}_{2}^{1}=\mathrm{F}^{2} \cdot \mathrm{W}^{2}{ }_{2} \ldots . \\
\mathrm{F}^{2}=6687,382 \mathrm{~kg} / \mathrm{jam}
\end{gathered}
$$

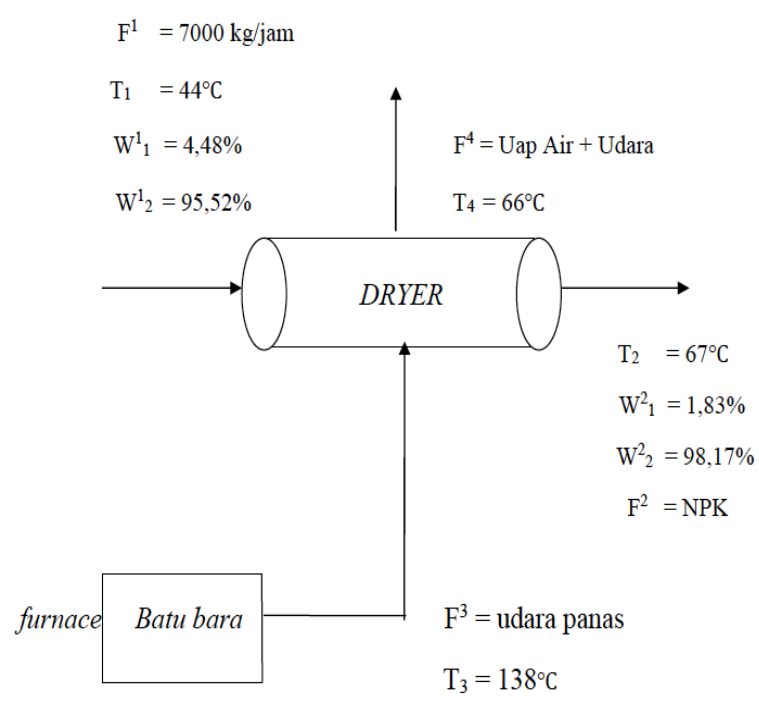

Gambar 2. Neraca Massa Proses Pengeringan Pupuk NPK

Dari perhitungan neraca komponen NPK diperoleh jumlah NPK yang keluar dari dryer sebesar 6687,382 kg/jam. Selanjutnya untuk menghitung kadar air yang teruapkan pada proses pengeringan pupuk NPK pada unit dryer dapat dihitung menggunakan rumus neraca massa pada persamaan (7).

$$
\begin{gathered}
\mathrm{F}^{4} \cdot \mathrm{W}^{4}{ }_{1}=\mathrm{F}^{1} \cdot \mathrm{W}^{1}{ }_{1}-\mathrm{F}^{2} \cdot \mathrm{W}^{2}{ }_{1} \ldots \ldots . .(7) \\
\mathrm{F}^{4} \cdot \mathrm{W}^{4}{ }_{1}=190,621 \mathrm{~kg} / \mathrm{jam}
\end{gathered}
$$

Dari perhitungan neraca komponen jumlah air yang teruapkan diperoleh jumlah air yang teruapkan pada unit dryer adalah $190,621 \mathrm{~kg} / \mathrm{jam}$. 
3.2. Penentuan Laju Udara Keluar dari Dryer

Untuk menentukan jumlah udara yang keluar dari unit dryer maka ditentukan terlebih dahulu komponennya yaitu debit aliran udara dan massa udara. Melalui perhitungan diperoleh debit aliran $\mathrm{Q}$ adalah 12380,141 $\mathrm{m}^{3} / \mathrm{jam}$ dengan luas penampang sebesar $1,719 \mathrm{~m}^{2}$ dan kecepatan udara $2 \mathrm{~m} / \mathrm{s}$. Kemudian massa udara diperoleh melalui perhitungan rumus sebesar 10637,512 kg/jam dengan massa jenis udara sebesar $0,8592 \mathrm{~kg} / \mathrm{m}^{3}$ melalui interpolasi data pada suhu $125{ }^{\circ} \mathrm{C}$ dan 150 ${ }^{\circ} \mathrm{C}$. Lebih lanjut, laju udara yang keluar dari unit dryer ditentukan dengan persamaan (8) yang sesuai pada Gambar 2, sehingga laju udara keluar dari unit dryer diperoleh sebesar 10828,133 kg/jam.

$$
\begin{gathered}
\mathrm{F}^{4}=\mathrm{F}^{3}+\mathrm{F}^{4} \cdot \mathrm{W}^{1}{ }_{4} \ldots \ldots \ldots \ldots \ldots \ldots . . . . .(8) \\
\mathrm{F}^{4}=10637,512 \mathrm{~kg} / \mathrm{jam}+190,621 \mathrm{~kg} / \mathrm{jam} \\
\mathrm{F}^{4}=10828,133 \mathrm{~kg} / \mathrm{jam}
\end{gathered}
$$

3.3. Jumlah Panas dan Batu Bara pada furnace dalam Pengeringan Pupuk NPK

Kapasitas panas dari komponen penyusun pupuk NPK formula 12.12.17 dengan metode Goodman [14] ditunjukkan pada Tabel 2 pada temperatur rata-rata 328 $\mathrm{K}$.

Tabel 2. Kapasitas Panas Beberapa Komponen Pupuk NPK

\begin{tabular}{ccc}
\hline Komponen & $\begin{array}{c}\text { Konstanta } \\
\text { (A) }\end{array}$ & $\begin{array}{c}\text { Cp.m } \\
\text { (Kkal/Kg.K) }\end{array}$ \\
\hline $\mathrm{CO}\left(\mathrm{NH}_{2}\right)_{2}$ & 14,099036 & 0,005542 \\
$\mathrm{P}_{2} \mathrm{O}_{5}$ & 7,791104 & 0,00126786 \\
\hline
\end{tabular}

Kapasitas panas dari komponen penyusun pupuk NPK formula 12.12.17 lainnya seperti $\mathrm{KCl}$ pada temperatur yang sama yaitu $328 \mathrm{~K}$ adalah sebesar 0,16396972 kkal/kg.K [14]. Kapasitas panas air pada temperatur $44{ }^{\circ} \mathrm{C}$ adalah 0,99825178 kkal/kg.K [16]. Dengan demikian maka kapasitas panas untuk pupuk NPK formula 12.12.17 ditentukan dengan persamaan (9), sehingga kapasitas panas total adalah 0,47589419 kkal/kg.K. Selanjutnya jumlah panas yang dibutuhkan untuk mengeringkan pupuk NPK pada unit dryer melalui perhitungan diperoleh sebesar 6136939,939 kkal/jam.

$$
\begin{gathered}
\mathrm{C}_{\mathrm{pNPK}}=\mathrm{C}_{\mathrm{pCO}(\mathrm{NH} 2) 2} \cdot \%_{\mathrm{CO}(\mathrm{NH} 2) 2}+\mathrm{C}_{\mathrm{pP} 2 \mathrm{O} 5} . \\
\% \mathrm{P} 2 \mathrm{O} 5+\mathrm{C}_{\mathrm{pKCl}} \cdot \%_{\mathrm{KCl}}+\mathrm{C}_{\mathrm{pH} 2 \mathrm{O}} \cdot \%_{\mathrm{H} 2 \mathrm{O}} \ldots . . .(9)
\end{gathered}
$$

Tabel 3. Tabulasi Data Jumlah Panas dan Kebutuhan Batu Bara

\begin{tabular}{ccccccc}
\hline No & \multicolumn{2}{c}{$\begin{array}{c}\text { Suhu } \\
\text { Pupuk NPK } \\
\left({ }^{\circ} \mathbf{C}\right)\end{array}$} & \multicolumn{2}{c}{$\begin{array}{c}\text { Kadar Air } \\
(\boldsymbol{\%})\end{array}$} & Jumlah Panas & Jumlah bahan bakar \\
\cline { 2 - 7 } & \multicolumn{1}{c}{$\boldsymbol{\text { Out }}$} & In & Out & Kkal/jam & Kg/jam \\
\hline 1 & 44 & 66 & 4,48 & 1,83 & 6136939,939 & 789,114 \\
2 & 45 & 65 & 4,48 & 1,82 & 6135565,430 & 789,322 \\
3 & 43 & 64 & 4,47 & 1,86 & 6136738,650 & 789,102 \\
4 & 44 & 65 & 4,46 & 1,84 & 6136443,760 & 789,237 \\
5 & 45 & 63 & 4,45 & 1,83 & 6135654,230 & 789,322 \\
\hline
\end{tabular}

Dengan diperolehnya nilai jumlah panas maka dapat ditentukan kebutuhan bahan bakar yang dibutuhkan untuk memanaskan udara dalam proses pengeringan pupuk NPK formula 12.12.17 yaitu sebesar 789,114 kg/jam. Dengan cara yang sama perhitungan kebutuhan panas dan kebutuhan bahan bakar pada 
pengeringan pupuk NPK pada unit dryer dilakukan seperti data 2,3,4,5 dan hasilnya ditunjukkan pada Tabel 3 .

\section{Kesimpulan}

Berdasarkan perhitungan yang telah dilakukan untuk mengeringkan pupuk

\begin{abstract}
NPK dengan kapasitas $7000 \mathrm{~kg} / \mathrm{jam}$ dibutuhkan energi sebesar 6136268,402 Kkal/jam Jumlah bahan bakar yang dibutuhkan untuk mengeringkan pupuk NPK adalah sebesar 789,219 kg/jam.
\end{abstract}

\section{Daftar Rujukan}

[1] Vasa, R., Ram, N., A, J. F., \& Karthick, P. (2018). Performance analysis of steam turbine in Thermal Power plant, International Journal of Trendy Research and Engineering and Technology, 2(3), 33-38. Retrieved from https://trendytechjournals.com/files/issues/volume2/issue3-8.pdf

[2] Srinivas, G. T., Kumar, D. R., Mohan, P. V. V. M., \& Rao, B. N. (2017). Efficiency of a Coal Fired Boiler in a Typical Thermal Power Plant. American Journal of Mechanical and Industrial Engineering, 2(1), 32. doi: 10.11648/j.ajmie.20170201.15

[3] Sagaf, M. (2018). Analisis faktor-faktor penyebab perubahan efisiensi boiler jenis pulverized coal fired forced circulation sub-critical pressure menggunakan metode tak langsung. Teknoin, 24(2), 147-158. doi: 10.20885/teknoin.vol24.iss2.art5

[4] Bureska-Joleska, L. (2017). Influence of coal quality to the boiler efficiency and opportunity for its improvement. Termotehnika, 43(1-4), 59-65. doi: 10.5937/termoteh1704059b

[5] Plutecki, Z., Sattler, P., Ryszczyk, K., Duczkowska, A., \& Anweiler, S. (2020). Thermokinetics of brown coal during a fluidized drying process. Energies, 13(3), 24-26. doi: 10.3390/en13030684

[6] Pusat, S., \& Erdem, H. H. (2017). Drying characteristics of coarse low-rank-coal particles in a fixed-bed dryer. International Journal of Coal Preparation and Utilization, 37(6), 303-313. doi: 10.1080/19392699.2016.1179638

[7] Rahman, R., Widodo, S., Azikin, B., \& Tahir, D. (2019). Chemical composition and physical characteristics of coal and mangrove wood as alternative fuel. Journal of Physics: Conference Series, 1341(5). doi: 10.1088/1742-6596/1341/5/052008

[8] Solahuddin, M. I. (2018). Analisis Pengaruh Perbedaan Nilai HHV (High Heating Value) Batubara Terhadap Gas Hasil Pembakaran pada Boiler. Jurnal Teknik Mesin ITI, 2(2), 30-34. doi: $10.31543 / \mathrm{jtm} . \mathrm{v} 2 \mathrm{i} 2.157$

[9] Medan, P. A. (2017). Katalog PT AGS Medan.

[10] Huang, Z. G., Weng, Y. X., Fu, N., Fu, Z. Q., Li, D., \& Chen, X. D. (2016). Modeling and Simulation of a Co-current Rotary Dryer. International Journal of Food Engineering, 12(2), 189-194. doi: 10.1515/ijfe-2015-0159

[11] Simanjuntak, M. E., Prabowo, Widodo, W. A., Sutrisno, \& Sitorus, M. B. H. (2019). Experimental and numerical study of coal swirl fluidized bed drying on 100 angle of guide vane. Journal of Mechanical Science and Technology, 33(11), 5499-5505. doi: 10.1007/s12206-019-1042-2

[12] Zainullin, L. A., Karelin, V. G., Artov, D. A., Epishin, A. Y., \& Spirin, N. A. (2017). Drying of Coal by a Solid Heat-Transfer Medium. Metallurgist, 60(9-10), 912-915. doi: 10.1007/s11015-017-0385-0

[13] Asdak, C. (1995). Hidrologi Pengolahan Daerah Aliran Sungai. Yogyakarta: UGM Press.

[14] Perry, R. H. (2008). Perry's Chemical Engineers' Handbook (Eight.). New York: McGrawHill.

[15] Dwi, R. C. (2008). Studi Perbaikan Kualitas Tegangan dan RugiRugi Daya pada Penyulang Pupur dan Bedak Menggunakan Bank Kapasitor, Trafo pengubah Tap dan Penggantian Kabel Penyulang. Universitas Indonesia.

[16] Reklaitis, G. V. (1983). Introduction to Material and Energy Balances. USA: John \&Wiley \& Sons, Inc. 